\title{
A Comparative Study of PM Synchronous Generator for Micro Hydropower Plants
}

\author{
A. DALCALI
}

\begin{abstract}
Developing technology and growing population are increasing the need of countries for energy every passing day. Renewable energy resources, which are an environmentally friendly and local solution alternative to fossil fuels, are seen to be a significant source of supply in this matter. Among renewable energy resources, hydroelectric energy is in an advantageous position with its reliable potential and sustainable production. With the purpose of utilizing small flowing waters such as rivers and streams and solving problems of access to interconnected grids in rural areas, micro-type hydroelectric power plants have a significant potential for countries. This study carried out the design and performance analyses of permanent magnet synchronous generators (PMSGs) with different numbers of poles for micro hydroelectric power plants. The generators' flux density values and total voltage harmonic distortions were examined. Additionally, the cogging torque magnitudes have been analyzed. The generators were loaded with nominal loads, and the time-dependent waveforms of phase voltages were obtained. By subjecting the obtained voltages to Fourier analysis, their harmonic spectrum was created. Finally, by considering the amount of active material used for the designs, their costs were compared.
\end{abstract}

Index Terms - Finite element analysis, Micro hydropower plant, Synchronous generator.

\section{INTRODUCTION}

$\mathrm{T}$ HE NEED for energy resources is increasing every day due to decreased fossil fuel resources, increased environmental concerns and population density. This has made energy supply one of the most important issues of today. Renewable energy resources (RER) are a significant solution for all these problems. The popularity of renewable energy is increasing as fossil fuels lead to environmental pollution and are being exhausted. In the period of 2000-2009, there were increases of $76 \%$ in oil prices, $114 \%$ in natural gas prices and $136 \%$ in coal prices. It is projected for the period of 2015 2040 that there will be increases of $186.3 \%, 85.7 \%$ and $56.3 \%$ in oil, natural gas, and coal prices, respectively. Considering the projections, it is important to increase renewable energy resources. Renewable energy is considered as inexpensive,

ADEM DALCALI, is with Department of Electrical and Electronics Engineering, Bandırma Onyedi Eylül University, Bandırma, Balıkesir, Turkey,(e-mail: adalcali@bandirma.edu.tr).

(iD https://orcid.org/0000-0002-9940-0471

Manuscript received December 04, 2020; accepted January 03, 2021. DOI: $10.17694 /$ bajece. 835836 local, and environmentally friendly energy. The main RERs may be listed as hydroelectric, biomass, geothermal, solar and wind energy. The most significant one among clean energy resources is hydroelectric energy [1,2] The main purpose of utilizing renewable energy resources is to reduce the emissions caused by fossil fuels, prevent global warming and climate change and achieve more effective usage of the assets of countries.

Hydroelectric energy plants are the most prevalently used plants in the world. They provide 19\% of the world's electricity [3]. Hydroelectric power plants may be categorized based on their power. It is possible to categorize those with a power of $100 \mathrm{MW}$ as large, those with a power of 15-100 MW as medium, those with a power of 1-15 MW as small, those with a power of $100 \mathrm{~kW}-1 \mathrm{MW}$ as mini, those with a power of $5 \mathrm{~kW}-100 \mathrm{~kW}$ as micro and those with a power of less than 5 $\mathrm{kW}$ as pico-hydroelectric power plants [4,5]. While largecapacity hydroelectric power plants supply electricity for several consumers, mini and micro types of hydroelectric plants usually appeal to grid-independent users [6,7]. Largescale hydroelectric plants have disadvantages such as high initial investment costs, long construction times, their disruption of ecological balance and the negative effects of their potential storage areas on life $[8,9]$. As opposed to large hydroelectric plants, there is no need to build a dam for micro hydroelectric plants. This prevents the disadvantages of high cost and long installation time. By achieving the right design in small-scale hydroelectric plants, the energy of flowing water may be directly converted into electricity with minimal harm on the environment [10,11]. Micro hydroelectric plants have a high efficiency, a high-capacity factor and a slow water velocity change regime. Turbine and generator selection is an important factor in micro hydroelectric power plants. Factors such as flow rate, head and slope of the water are effective in this selection. Another important parameter in turbine selection is the specific speed of the turbine $[12,13]$. These plants can operate independently from the grid or in connection with the grid. Small and micro hydroelectric plants use self-excited synchronous reluctance generators [10], PMSGs [14], and asynchronous generators [15]. However, as there is no separate field winding in asynchronous generators, there is a need for a group of capacitors that need to be connected in parallel to the generator. PM generators are frequently used in micro hydroelectric facilities. In small hydroelectric plants where PM generators are used, higher efficiency may be obtained in comparison to plants with asynchronous machines [16]. Considering the literature, this 
study carried out designs, performance analyses and cost comparisons of PMSGs with pole numbers of 10 and 16 for micro hydroelectric power plants.

\section{Permanent Magnet Synchronous Generator}

While designing electric machinery, the smallest volume, the lowest amount of material and the highest power density are desired. PMSGs are machines that have high power density, high efficiency and low torque ripple [17]. PM materials may be grouped as Alnico, ferrite and rare earth magnets. The quality of a PM is characterized by the maximum energy product that is obtained by multiplying the magnetic flux density $(\vec{B})$ and the magnetic field strength $(\vec{H})$. Neodymium magnets have high $\mathrm{BH}_{\max }$ products and are prevalently used in electric machinery. By using these magnets, it is possible to obtain compact machines with a high air-gap flux density [18]. PM machines are frequently preferred especially for lowspeed and variable-speed applications. Improvements in driver technology in parallel with the developments in elements of power electronics have increased the usage of PM machines $[19,20]$.

The design of electric machinery starts with sizing equations. The size of the machine that are obtained as a result of sizing calculations are usually associated with a set of assumptions and expectations that are not directly specified in the equation. In this sense, in sizing, the experience of the designer has importance in terms of meeting expectations. The general equation that is used for sizing electric machinery [21,22]:

$$
S=11 K_{w 1} * \bar{B} * a c *\left(\frac{D}{1000}\right)^{2} * \frac{L}{1000} * n
$$

In the equation, $S$ is the power (VA), $K_{w 1}$ is the winding coefficient, $\vec{B}$ is the specific magnetic loading (Tesla), ac is the specific electrical loading $(\mathrm{A} / \mathrm{m}), D$ is the stator diameter (mm), $L$ is the outer length ( $\mathrm{mm}$ ), and $n$ is the nominal speed (rpm). The remaining mathematical model of the PMSG, not present in this paper, may be found in detail $[22,23]$. The generators are $5 \mathrm{~kW}$, internal-rotor, and surface-mounted magnets. Table I shows the detailed design parameters. From here on, the 10-pole generator will be referred to as Design A, while the 16-pole generator will be described as Design B.

TABLE I

DESIGN PARAMETERS

\begin{tabular}{|c|c|c|c|}
\hline & Parameter & Design A & Design B \\
\hline \multirow{5}{*}{$\frac{\mathfrak{s}}{\tilde{t}}$} & Stator outer/inner diameter(mm) & $320 / 235$ & $450 / 340$ \\
\hline & Length (mm) & 91.5 & 65.5 \\
\hline & Stator material & M19 & M19 \\
\hline & Number of slots & 60 & 96 \\
\hline & Skew & 0.7 & 0.7 \\
\hline \multirow{3}{*}{$\stackrel{\overrightarrow{0}}{0}$} & Rotor outer diameter (mm) & 233 & 338 \\
\hline & Rotor inner diameter (mm) & 170 & 250 \\
\hline & Rotor material & M19 & M19 \\
\hline \multirow{4}{*}{ 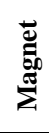 } & Embrace & 0.7 & 0.7 \\
\hline & Offset & 50 & 100 \\
\hline & Magnet material & N40UH & N40UH \\
\hline & Magnet thickness $(\mathrm{mm})$ & 9.1 & 9.8 \\
\hline
\end{tabular}

Fig. 1 shows the 3D model of the generators that have been designed.

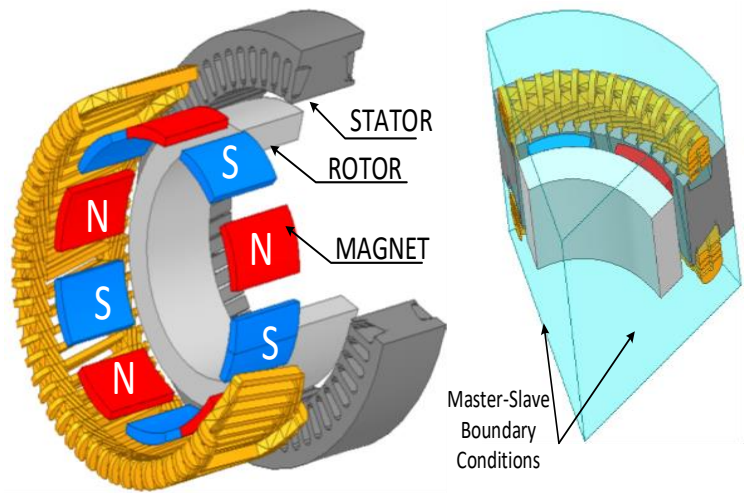

(a)

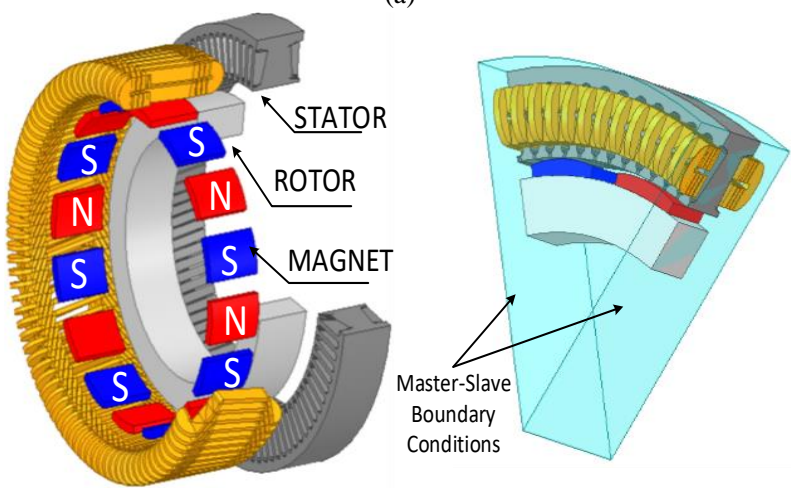

(b)

Fig.1. Exploded view of the generators, a) Design A, b) Design B

\section{ANALYSIS OF THE PERFORMANCE AND COST OF THE DESIGNED GENERATORS}

In generators that are designed, both the number of poles and the number of stator slots vary. The variation in these parameters leads to performance changes such as changes in the induced voltage and efficiency by changing the air-gap flux waveform. All these parameter changes determine the total amount of magnets and change the total cost of the generator. The design of electric machinery is complicated in its nature. Therefore, to obtain a satisfactory design, several interrelated problems need to be solved. Mathematics-based tools have been developed for solution of such complicated problems. One of the most effective ones among these is the Finite Element Method (FEM). FEM is a method that is used to obtain the solutions of amounts that are continuous in a certain region whose changes in the region where they are continuous may be represented by partial differential equations. By using this method, it is possible to obtain the electromagnetic parameters of a generator with high accuracy $[24,25]$. The mesh structure in the generators was created automatically with the help of a computer program. However, the density of the meshes was increased by the designer, particularly around the air gaps. In this study, the number of meshes created for Design A was 66482, whereas that for Design B was 74709. However, the point that requires attention here is that both generators were analyzed through the cross-section of a part to save time. Table II shows the 
results of the analyses on the designs that were carried out with no-load and rated load.

TABLE II ANALYSIS RESULTS

\begin{tabular}{clcc}
\hline & \multicolumn{1}{c}{ Parameter } & Design A & Design B \\
\hline \multirow{2}{*}{ Nominal } & Output power (W) & 5001 & 5001 \\
load & Efficiency (\%) & 92.3 & 92.4 \\
& Total loss (W) & 242.1 & 238.5 \\
\hline \multirow{2}{*}{ No load } & Stator yoke flux density (T) & 1.69 & 1.71 \\
& Rotor yoke flux density (T) & 1.03 & 0.56 \\
& Cogging torque (Nm) & 0.24 & 0.18 \\
\hline
\end{tabular}

Considering the cogging torque values that occurred out of the interaction between the magnet and the stator slots in PMs, a lower cogging torque value was obtained in Design B with higher numbers of poles and slots as expected. The results of the analysis in the unloaded state showed the suitability of the core geometry that was created and the magnetic material that was selected. The flux density value at which the generator core is to be operated is determined based on the point under the saturation region where the permeability is the maximum. In this context, the results that were obtained were suitable for the criteria that were targeted. Analyses with FEM require long times of solution. By using the boundary condition of symmetry, $1 / 5$ part of the 10 -pole generator and $1 / 8$ part of the 16-pole generator were obtained in the study. The analyses were carried out on these parts. In electric machinery, magnetic fields may be shown with Maxwell Equations:

$\nabla \times \bar{E}=-\frac{\partial \bar{B}}{\partial t} \quad \nabla \times \bar{H}=\bar{J}$

where, $\vec{E}$ is the electrical field strength, and $\vec{J}$ is the current density [26]. To define the magnetic vector potential in terms of magnetic flux density:

$$
\bar{B}=\nabla \times \bar{A}
$$

The main formula of the vector potential for the magnetic field is shown:

$$
\nabla \times(v \nabla \times \bar{A})=\bar{J}
$$

In the equation, as the curve $B=f(H)$ is not linear, $v$ shows variable conductance. The flux density distribution obtained on the generator core is obtained by Eq 5 and 6 [26]:

$$
\frac{\partial}{\partial x}\left(v \frac{\partial A}{\partial x}\right)+\frac{\partial}{\partial y}\left(v \frac{\partial A}{\partial y}\right)+\frac{\partial}{\partial z}\left(v \frac{\partial A}{\partial z}\right)=-\bar{J}
$$

In $3 \mathrm{D}$ analyses, the components of the magnetic flux density value in the $\mathrm{x}, \mathrm{y}$ and $\mathrm{z}$ axes are found as:

$$
B=\sqrt{B_{x}^{2}+B_{y}^{2}+B_{z}^{2}}
$$

In 2D modeling, fringing and end winding effects are not properly accounted. Therefore, it is a sturdier approach to create a 3D model of the machine. It would be possible to design a more realistic generator in terms of implementation by also addressing the presence of such effects through $3 \mathrm{D}$ modeling. For these reasons, the generators were analyzed through their 3D models [24]. The magnetic flux distribution that was obtained in the transient analyses on the part crosssection models is given in Fig. 2.

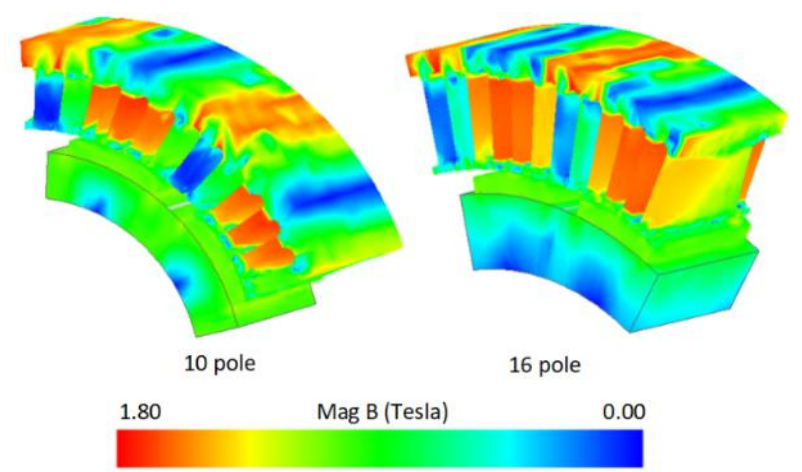

Fig. 2. Flux density distribution in part cross-sections

Because the saturation point of the M19-24G material is approximately $1.9 \mathrm{~T}$, the distributions of flux obtained on the core indicate that the operation was taking place below the saturation point. Because flux concentrated on stator notches, the density of flux was found to be relatively higher there in comparison to the other areas. For the generators, whose suitable magnetic flux distributions were obtained, nominally loaded state analyses were carried out in the next step, and voltage waveforms were derived.

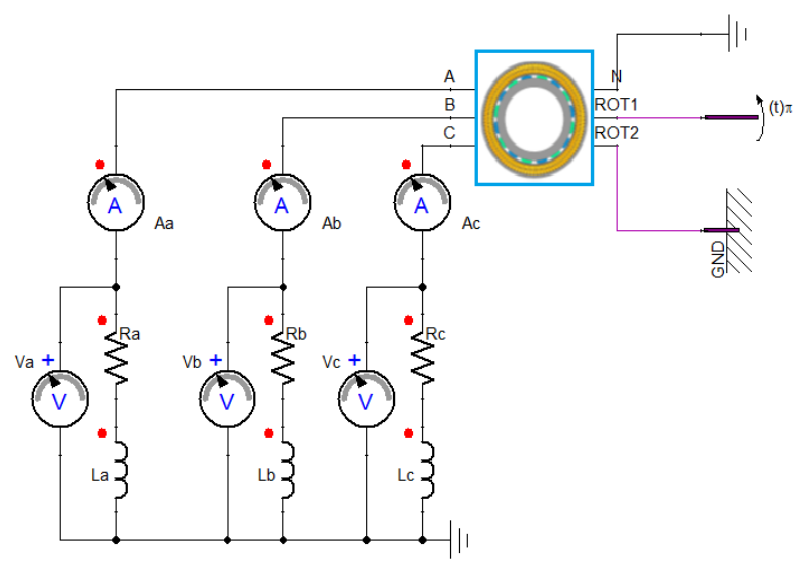

Fig. 3. Co-simulation model with nominal load

Nominal loads were attached to the generators, and their performances at the nominal speeds (600 rpm for Design A and $375 \mathrm{rpm}$ for Design B) were applied. An ohmic value of $26 \mathrm{ohms}$ and an inductive load of $27.42 \mathrm{mH}$ are connected to each phase. The circuit schema that was created is presented in Fig. 3. Fig. 4 shows the phase voltage waveforms of both generators. 


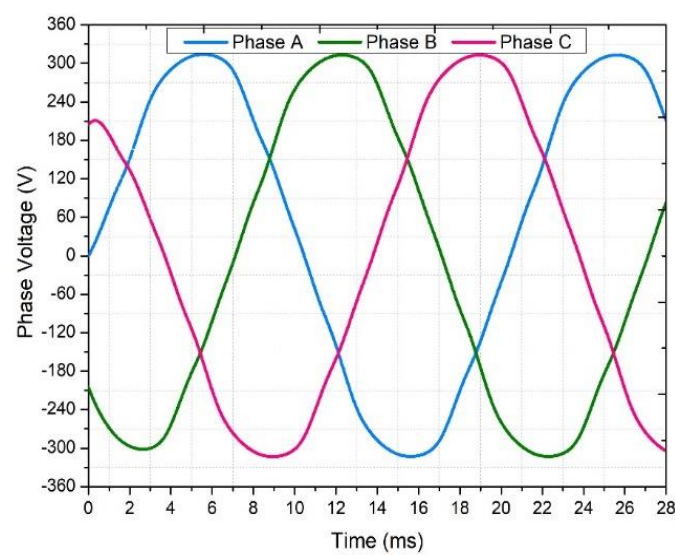

(a)

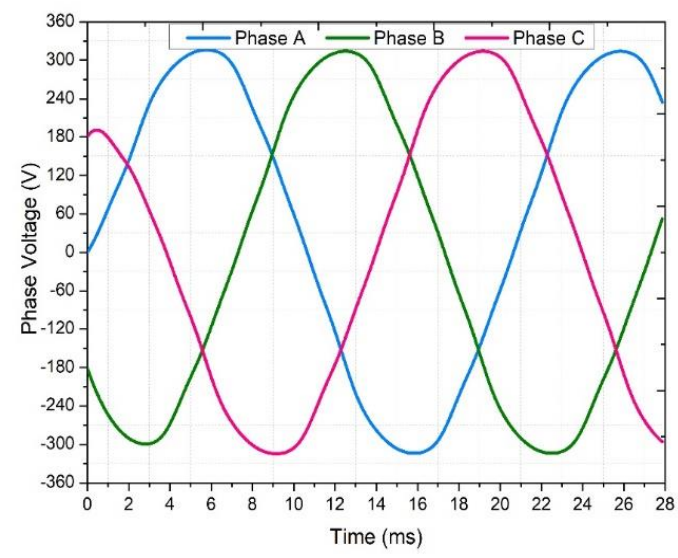

(b)

Fig. 4. Phase voltage, a) Design A, b) Design B

Harmonics are the full multiples of the fundamental frequency, and they lead to ripples in load current and voltage. Two types of harmonics as time and space harmonics may be considered for electric machinery. The effects of space harmonics may be changed by the physical changes to be made in the machine [23]. Analyses of the harmonic values of the designed generators need to be carried out. Fourier analyses of the generators may be calculated by using the graphical method. In this method, the Fourier coefficients may be derived by using [27].

$$
\begin{aligned}
& A_{n}=\frac{2}{m} \sum_{k=1}^{m}\left(y_{k} \cos \left(n \theta_{k}\right)\right) \\
& B_{n}=\frac{2}{m} \sum_{k=1}^{m}\left(y_{k} \sin \left(n \theta_{k}\right)\right)
\end{aligned}
$$

In the equation, $m$ is the number of vertical separations, and for the harmonic analysis to be sensitive, it needs to be at the maximum value. However, the number of operations increases as the number of separations increases [23]. The function of the phase voltage induced by the $A_{n}$ and $B_{n}$ coefficients is expressed by:

$$
\begin{aligned}
& V(\theta)=\left(\sqrt{A_{1}^{2}+B_{1}^{2}}\right) \cdot\left(\sin \left[\theta+\tan ^{-1}\left(\frac{B_{1}}{A_{1}}\right)\right]\right)+\ldots \\
& +\left(\sqrt{A_{n}^{2}+B_{n}^{2}}\right) \cdot\left(\sin \left[\theta+\tan ^{-1}\left(\frac{B_{n}}{A_{n}}\right)\right]\right)
\end{aligned}
$$

The value of the phase voltage is expressed as some of the base component (1st harmonic) and harmonic components. As mentioned before, the distortions in the waveform of voltage are known as the Total Harmonic Distortion (THD) and expressed in \%. The THD value is found by using [28]:

$T H D_{V}=\frac{\sqrt{\sum_{2}^{\infty} V_{n}^{2}}}{V_{1}}$

Fourier analyses have been carried out using the MATLAB software (License No: 40692431) to obtain their harmonic spectrum. Fig. 5 features the harmonic spectrum of the designs.

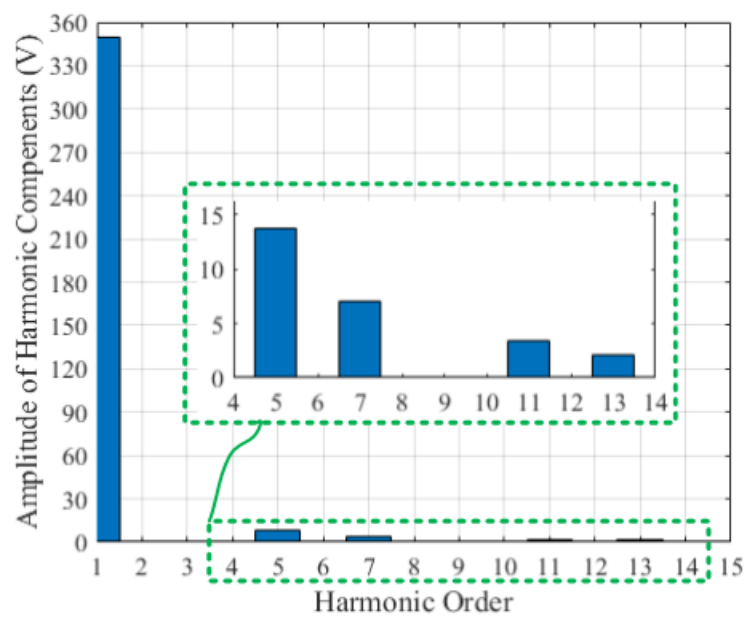

(a)

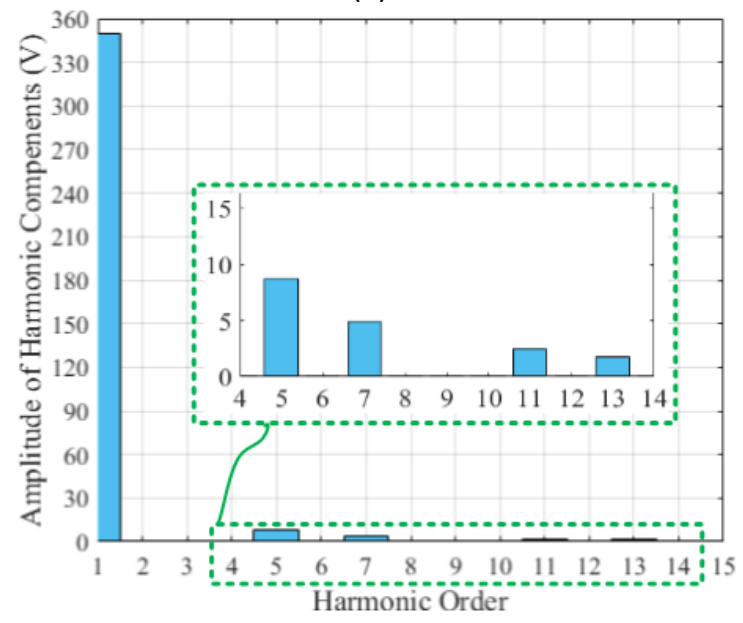

(b)

Fig. 5. Harmonic spectrum of the generators at phase voltage, a) Design A, b) Design B

At nominal loading, the harmonic distortions of the 16-pole 
generator were relatively lower than those of the 10-pole generator. Design A had higher low-order harmonics than the other design. Machines with PMs have a significant disadvantage in spite of their efficiency and power density advantages. The cogging torque that occurs in machines with PMs can cause noise, vibration and have ripple of torque $[29,30]$. While the stator currents of both generators are zero, the variation of cogging torque with the rotor position is given in Fig. 6.

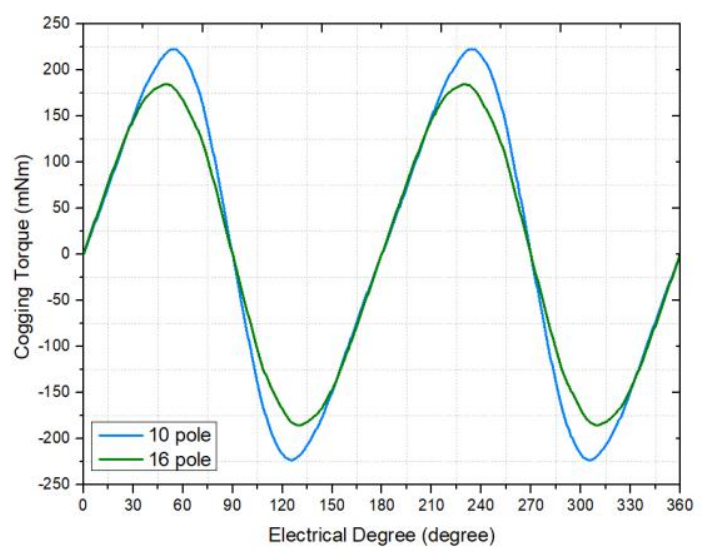

Fig. 6. Cogging torque variation of design

TABLE III

Design $\mathrm{B}$ with a higher number of poles and slots had a smaller cogging torque as expected. Because it had a greater number of slots and poles, the variation in its reluctance was reduced, and thus, the value of its cogging torque decreased.

Finally, cost analyses were performed on the generators whose magneto-static and transient performances were examined. As known, a large part of the cost in PM machines is created by the magnets. In the cost calculations, it was accepted that, N40UH: 95 \$/kg, M19: 1.9 \$/kg and Copper: 6 \$/kg [21]. The material amounts that were used in the designs and their costs are shown in Table III.

As N40UH-type magnets were used for both designs in the study, and magnet usage was expressed in $\mathrm{kg}$. As seen in the table, changing magnet geometries lead to significant differences in the total material costs. Magnet cost has the largest share among the costs of active materials. Based on the costs, Design A is $16.34 \%$ more economical. The weights of the generators were $38.47 \mathrm{~kg}$ for Design A and $48.05 \mathrm{~kg}$ for Design B.

\begin{tabular}{|c|c|c|c|c|c|c|c|}
\hline \multirow[t]{2}{*}{ Design } & \multicolumn{2}{|c|}{ Magnet (N40) } & \multicolumn{2}{|c|}{ Core Material (M19) } & \multicolumn{2}{|c|}{ Coil (Copper) } & \multirow[t]{2}{*}{ Total Cost (\$) } \\
\hline & Amount (kg) & Cost $(\$)$ & Amount (kg) & Cost $(\$)$ & Amount (kg) & Cost $(\$)$ & \\
\hline Design A & 2.82 & 267.9 & 25.56 & 48.56 & 10.09 & 60.54 & 377 \\
\hline Design $B$ & 3.19 & 303.05 & 32.67 & 62.07 & 12.19 & 73.14 & 438.26 \\
\hline
\end{tabular}

\section{CONCLUSION}

This study carried out the design and performance comparisons of PM multi-pole synchronous generators with the power of $5 \mathrm{~kW}$ that are suitable for micro hydroelectric power plants. For a fair comparison, the core and magnet materials of the generator were selected as the same. The analyses of the generators at nominal load and no-load showed that the flux density distributions were within the desired limits considering the core material that was used. In Design $\mathrm{B}$, which had higher numbers of slots and poles, the cogging torque value was $25 \%$ less than that in Design A. Considering the total harmonic distortions of the voltages at the nominal load, Design B had lower harmonic components with the value of $2.73 \%$. Although the provide similar efficiency values, designs with high THD values may lead to significant problems such as acoustic noise, vibration, and saturation at the core. Therefore, although the values of these generators with different numbers of poles such as efficiency and power factor could be close, THD values have a significant effect on the operational performance of the generator, and they need to be as low as possible. The 10-pole design required $26.21 \%$ less material usage than the 16-pole design. The amount of especially the magnets, which is a substantial component of costs, was relatively higher in the 16-pole generator. This situation is the main reason for the difference between the costs of the two designs. In terms of the total costs of the materials that were used, Design A was $16.34 \%$ more economical. Considering the designs in general, Design B could produce the same power with approximately the same efficiency at a lower speed. Additionally, lower \%THD could be obtained with the 16-pole design for the unloaded and nominally loaded states. However, a lighter generator and a lower-cost structure could be achieved by using less materials with Design A. Therefore, it would be a better approach for designers to consider several outputs rather than one output such as efficiency, cost and torque and assess their designs in this direction. With this study, it was aimed to provide a general idea for designers on the behaviors of PMSGs with different numbers of poles in both magnetostatics and transient state.

\section{REFERENCES}

[1] Electricity Generation Sector Report, Electricity Generation Corp., Ankara, Turkey, Tech. Rep. Jan. 2011.

[2] İ. Yavuz, H. Özbay, "Installation and Maintenance Processes in Wind Turbines: The Case of Bandırma." Journal of Engineering Sciences and Researches, vol. 2, 2, 2020, pp. 58-68.

[3] J.A. Laghari, H, Mokhlis, A. H. A. Bakar, H. Mohammad, "A comprehensive overview of new designs in the hydraulic, electrical equipments and controllers of mini hydro power plants making it cost effective technology." Renewable and Sustainable Energy Reviews, vol. 20, 2013, pp. 279-293. 
[4] C.P. Jawahar, P.A. Michael, "A review on turbines for micro hydro power plant." Renewable and Sustainable Energy Reviews, vol. 72, 2017, pp. 882-887.

[5] B.A. Nasir, "Design of micro-hydro-electric power station." International Journal of Advanced Technology and Engineering Exploration, vol. 2, 5, 2013, pp. 39-47.

[6] S. Lajqi, N. Lajqi, B. Hamidi, "Design and construction of mini hydropower plant with propeller turbine." International Journal of Contemporary ENERGY, vol. 2, 1, 2016, pp. 1-13.

[7] A.T. Cordoba, D.G. Reina, P.M. Gata, "An evolutionary computational approach for designing micro hydro power plants." Energies, vol. 12, 5, 2019, pp. 1-25.

[8] M.M. Rahman, P. Chowdhury, M. N. Rahman, S. T. Mowri, M.A Mamun, "Portable micro hydro electrical generator." IOSR Journal of Electric and Electronics Eng, vol. 6, 3, 2011, pp. 39-43.

[9] L. Belhadji, S. Bacha, D. Roye, "Modeling and control of variable-speed micro-hydropower plant based on axial-flow turbine and permanent magnet synchronous generator (MHPP-PMSG)." 7th Annual Conference of the IEEE Industrial Electronics Society, Melbourne, Australia, 2011, pp. 896-901.

[10] J Awad, H. Wadi, M., E., Hamdi, "A self-excited synchronous generator for small hydro applications." International Conference Energy, Environmental, Ecosystems, and Sustainable Development, 2005, pp. 15

[11] S. Zeb, M. Ali, A. Mujeeb, H. Ullah, "Cost efficient mini hydro plant with low water head whirlpool design methodology for rural areas (micro hydro whirlpool power plant)." 2nd International Conference on Computing, Mathematics and Engineering Technologies, Pakistan, 2019, pp. 1-7.

[12] T.C. Yan, T. Ibrahim, N.M. Nor, "Micro hydro generator applied on domestic pipeline." International Conference on Electrical Engineering and Informatics, Indonesia, 2011, pp. 1-6.

[13] B. A. Nasir, "Suitable selection of components for the micro-hydroelectric power plant." Advances in Energy and Power, vol. 2, 1, 2014 , pp. 7-12.

[14] B. Guo, S. Bacha, M. Alamir, A. Mohamed, "Variable speed microhydro power generation system: review and experimental results." 3ème édition du Symposium de Génie Electrique, Nancy, France, 2018.

[15] W. Ali, H. Farooq, A. U. Rehman, M. Jamil, Q. Awais, A. Mohsin, "Grid interconnection of micro hydro power plants: major requirements, key issues and challenges." International Symposium on Recent Advances in Electrical Engineering (RAEE), Islamabad, 2018, pp. 1-6.

[16] Z. Goryca, S. Rozowicz, K. Dabala, Z. Krzemien, "Design and tests of generators for micro hydro plants." International Symposium on Electrical Machines, Poland, 2017, pp. 1-4.

[17] B.O. Zala, V. Pugachov, "Methods to reduce cogging torque of permanent magnet synchronous generator used in wind power plants." Elektronika Ir Elektrotechnika, vol. 23, 1, 2017, pp. 43-48.

[18] N. Öztürk, A. Dalcal, E. Çelik, S. Sakar, "Cogging torque reduction by optimal design of PM synchronous generator for wind turbines." International Journal of Hydrogen Energy, vol. 42, 28, 2017, pp. 1759317600.

[19] H. Gör, E. Kurt, "Preliminary studies of a new permanent magnet generator (PMG) with the axial and radial flux morphology," International Journal of Hydrogen Energy, vol.11, 17, 2016, pp.70057018.

[20] O. Lyan, V. Jankunas, E. Gusemnoviene, A. Pasilis, A. Senulis, A. Knolis, E. Kurt, "Exploration of a Permanent Magnet Synchronous Generator with Compensated Reactance Windings in Parallel Rod Configuration." Journal of Electronic Materials, vol. 47, 8, 2018, pp. 4437-4443.

[21] A. Dalcal1, "Cogging torque analysis in permanent magnet synchronous generators using finite elements analysis", International Transactions on Electrical Energy Systems, vol. 30, 10, 2020.

[22] Y. Duan, "Method for design and optimization of surface mount permanent magnet machines and induction machines." Ph.D. dissertation, Dept. Elect. Comp. Eng., Georgia Institute of Tech., USA, 2010.

[23] A. Dalcal, M. Akbaba, "Optimum pole arc offset in permanent magnet synchronous generators for obtaining least voltage harmonics." Scientia Iranica, vol.24, 6, 2017, pp. 3223-3230.

[24] S.L. Ho, W.N. Fu, "Review and future application of finite element methods in induction motors." Electric Machines \& Power Systems, vol. 26, 2, 1998, pp. 111-125.
[25] A. Alaeddini, H. Tahanian, A. Darabi, "Impact of Number of Phases on Electromagnetic Torque Characteristics of Transverse Flux Permanent Magnet Machines." Advanced Electromagnetics, vol. 8, 4, 2019, pp. 118-129.

[26] M. Akbaba, S.Q. Fakhro, "Field distribution and iron loss calculation in the reluctance augmented shaded pole motors using finite element method." IEEE Transactions on Energy Conversion, vol. 7, 2, 1992, pp. 302-307.

[27] C. Kocatepe, M. Uzunoğlu, R. Yumurtac1, A. Karakas, O. Arıkan, Harmonics in Electrical Installations, Istanbul, Turkey: Birsen Publication, 2003. (In Turkish).

[28] S.B. Efe, "Harmonic filter application for an industrial installation." 13th International Conference on Engineering of Modern Electric Systems (EMES), Romania, 2015, pp. 31-34.

[29] H. Gör, E. Kurt, "Waveform characteristics and losses of a new double sided axial and radial flux generator," International Journal of Hydrogen Energy, vol. 41, 29, 2016, pp. 12512-12524.

[30] S. Leitner, H. Gruebler, A. Muetze, "Cogging Torque Minimization and Performance of the Sub-Fractional HP BLDC Claw-Pole Motor." IEEE Transactions on Industry Applications, vol. 55, 5, 2019, pp. 4653-4664.

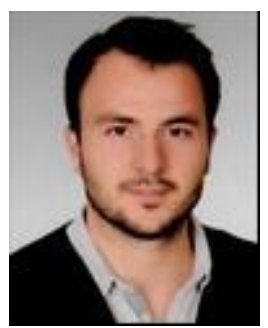

\section{BIOGRAPHY}

ADEM DALCALI received B.Sc. and M.Sc. degree from Gazi University, Ankara in 2010 and 2013, respectively. He received the Ph.D. degree in Electric and Electronics Engineering from Karabük University, Turkey, in 2017. From 2013 to 2017, he was a Research Assistant at Department of Electric and Electronics Engineering, Karabük University. $\mathrm{He}$ is currently an Assistant Professor at Department of Electrical-Electronics Engineering, Bandirma Onyedi Eylül University. His research interests wind energy and the numerical analysis of the electromagnetic field in electrical machinery. 